\title{
Giant Congenital Melanocytic Nevus in a Chinese Newborn
}

\author{
Weizhao Lin (1D) ${ }^{1, *}$ \\ Yixuan Zhou ${ }^{2} * *$ \\ Ruiman $\mathrm{Li}^{1}$ \\ 'Department of Obstetrics and \\ Gynecology, The First Affiliated Hospital \\ of Jinan University, Guangzhou, \\ Guangdong, People's Republic of China; \\ ${ }^{2}$ The First Clinical Medical College of \\ Jinan University, Guangzhou, Guangdong \\ People's Republic of China
}

*These authors contributed equally to this work
Correspondence: Ruiman Li Department of Obstetrics and

Gynecology, The First Affiliated Hospital of Jinan University, 613 Huangpu Road

West, Guangzhou, Guangdong, 510630 ,

People's Republic of China

Email liruiman2020@I26.com

\begin{abstract}
Giant congenital melanocytic nevus (GCMN) is a rare birthmark disorder that reportedly affects 1 in 20,000-500,000 live births. Here, we present a case of GCMN in a 1-day-old newborn that covered the entire abdomen, reaching the thigh and chest, and laterally toward the backward aspect of the trunk to involve the entire back and buttocks. We discuss the diagnostic and treatment approach.
\end{abstract}

Keywords: congenital melanocytic nevus, malignant transformation, diagnosis, treatment

\section{Introduction}

Congenital melanocytic nevi (CMNs) are melanocytic proliferations that typically present on the skin at birth or shortly thereafter and are classified primarily based on their size. Giant congenital melanocytic nevus (GCMN) is defined as those CMNs that are predicted to be $\geq 40 \mathrm{~cm}$ in diameter by adulthood and that may become complicated by melanoma, neurocutaneous melanocytosis (NCM), pain, pruritus, hypohidrosis, or cosmetic disfigurement. Although CMNs are relatively common, GCMN is a rare entity with a reported incidence of only 1 in 20,000-500,000 live births. ${ }^{1}$ GCMN is mainly diagnosed clinically, but this can be combined with histological findings. Reports of GCMNs are less common in China. Here we report a case of GCMN in a Chinese 1-day-old newborn with the aim of bringing this pathology to the attention of clinicians.

\section{Case Report}

A male Chinese neonate weighing $3300 \mathrm{~g}$ was born through normal natural vaginal delivery after a 40 -week pregnancy. A giant melanocytic nevus was observed at the birth that covered his entire abdomen, reaching the thigh and chest, and laterally toward the backward aspect of his trunk to involve the entire back and buttocks (Figure 1A and B). The giant pigmented lesion was dark brown to black and had a rough surface, with irregular borders and pigmentation in the peripheral areas, but without elevation from the surrounding tissue since no nodular areas were detected on palpation (Figure 1C). The patient was in good condition other than the cutaneous findings. The patient was enrolled in monthly follow-up examinations by a dermatologist, and followed up by plastic surgeons and a pediatrician.

\section{Discussion}

CMNs are benign proliferations of abnormal melanocytes originating in utero, being derived from the neural crest. ${ }^{2}$ They can appear in various locations, develop 


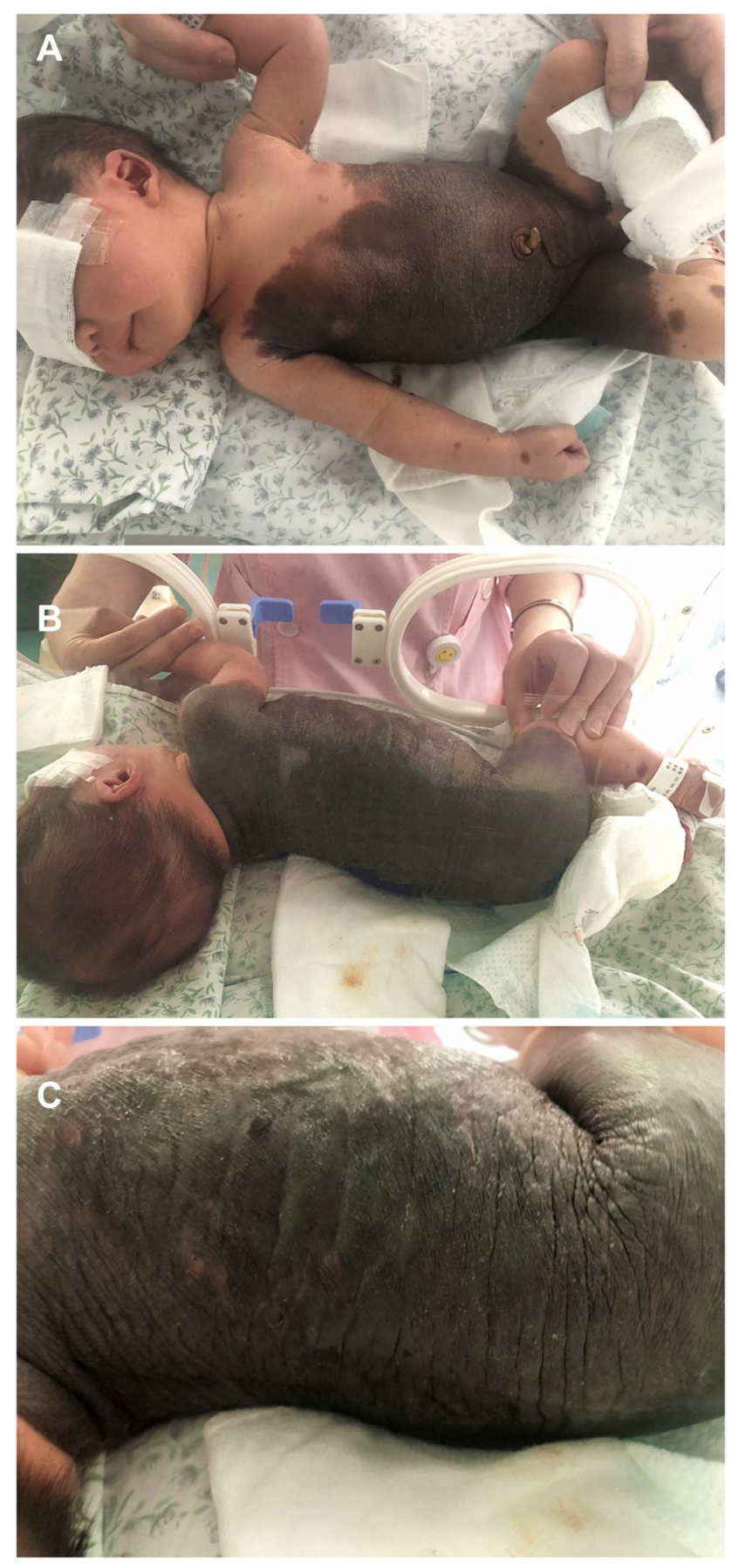

Figure I (A) Clinical manifestation of a giant congenital melanocytic nevus (GCMN) covering the entire abdomen and reaching the thigh and chest of a I-dayold newborn. (B) The GCMN completed covered the backward aspect of the trunk to involve the entire back and buttocks. (C) The giant pigmented lesion was dark brown to black and had a rough surface, with irregular borders and pigmentation in the peripheral areas, but without elevation from the surrounding tissue since no nodular areas were detected on palpation.

from the 5th week of pregnancy, and then subsequently migrate from the neural crest to locations including the skin, mucosa, eyes, and meninges. Dysregulation of this process leads to aberrant growth, resulting in the occurrence of melanocytic nevi. ${ }^{3}$ Size is the principal criterion for categorizing CMNs. ${ }^{4} \mathrm{CMNs}$ are usually classified according to the maximum size that they are expected to attain by the projected adult size (PAS). It is estimated that about $1 \%$ of newborns have a $\mathrm{CMN},{ }^{5}$ most of which are classified as a small $(\mathrm{PAS}<1.5 \mathrm{~cm}$ ) or moderate-size $(\mathrm{PAS}=1.5-19.9 \mathrm{~cm})$. Large and giant $\mathrm{CMNs}$ (PAS $\geq 20$ and $\geq 40 \mathrm{~cm}$, respectively) are rarer, with the estimated incidence ranging from 1 in 20,000-500,000 live births. ${ }^{1}$

CMN may also undergo malignant transformation, among which the risk of transforming large and giant CMN into malignant melanoma is $2 \%{ }^{2}$ Risk factors for malignant transformation include the presence of three or more nevi, nevi $>20 \mathrm{~cm}$, and earlier onset. ${ }^{6}$ Despite its rarity, GCMN is of considerable interest due to its potentially severe complications-melanoma and NCM-that are associated with involvement of the central nervous system. ${ }^{7}$ It is therefore recommended that the examination includes CT, MRI, and/or PET, combined with dermoscopy. About half of the malignant transformation cases happened before adolescence, so many surgeons emphasize the importance of the early and complete excision of CMNs. The primary indication for CMN excision is the presence of high-risk phenotypical features, which include size (giant nevi), trunk location, and irregular morphology. ${ }^{8}$ The second indication for surgery is functional issues relating to the lesion, with the most commonly complaints being pruritus, intertrigo, and seborrheic discharge. There are a variety of treatment methods for GCMN. Treatment should be individualized by considering the age of the patient, the size and location of the lesion, the risks of melanoma and $\mathrm{NCM}$, and the presence of other congenital malformations or complications. ${ }^{9}$ Treatment of GCMN ranges from watchful waiting to less invasive procedures (laser treatment, curettage, chemical peels) to more extensive procedures (tissue expansion, or serial excision with staged direct closure, integra dermal regeneration). In particular, the integra dermal regeneration is very important for newborns. Not only does it reduce the donor-site morbidity, but it also allows access to thinner split-thickness skin grafts. ${ }^{10}$ Since the number of melanocytes is associated with an increased malignant potential, treatment with laser can destroy melanocytes, thereby reducing the risk of melanoma. In addition, for cosmetically sensitive areas, laser treatment can be combined to greatly improve the patient's appearance and function. ${ }^{11}$ 
In the present case we decided to perform integra dermal reconstruction and laser treatment. We consider this approach an effective prevention and curative option that considers the risks associated with further transformation as well as the aesthetic outcomes, while also aiming to avoid any psychoemotional negative impact on patients from childhood onward. We believe that frequent followup visits and attentive parental care are crucial to achieving a positive outcome.

\section{Patient Consent}

The authors certify that they have obtained all appropriate patient consent forms. The parents of the baby provided informed consent for publication of the case details and images. Institutional approval is not required for this case study.

\section{Disclosure}

The authors declare no potential conflicts of interest.

\section{References}

1. Vourc'h-Jourdain M, Martin L, Barbarot S. aRED. Large congenital melanocytic nevi: therapeutic management and melanoma risk: a systematic review. J Am Acad Dermatol. 2013;68(3):493-498.e114. doi:10.1016/j.jaad.2012.09.039

2. Moustafa D, Blundell AR, Hawryluk EB. Congenital melanocytic nevi. Curr Opin Pediatr. 2020;32(4):491-497. doi:10.1097/ MOP.0000000000000924
3. Viana AC, Gontijo B, Bittencourt FV. Giant congenital melanocytic nevus. An Bras Dermatol. 2013;88(6):863-878. doi:10.1590/ abd1806-4841.20132233

4. Zaal LH, Mooi WJ, Sillevis Smitt JH, van der Horst CM. Classification of congenital melanocytic naevi and malignant transformation: a review of the literature. Br J Plast Surg. 2004;57 (8):707-719. doi:10.1016/j.bjps.2004.04.022

5. Kanada KN, Merin MR, Munden A, Friedlander SF. A prospective study of cutaneous findings in newborns in the United States: correlation with race, ethnicity, and gestational status using updated classification and nomenclature. $J$ Pediatr. 2012;161(2):240-245. doi:10.1016/j.jpeds.2012.02.052

6. Arneja JS, Gosain AK. Giant congenital melanocytic nevi. Plast Reconstr Surg. 2007;120(2):26e-40e. doi:10.1097/01 prs.0000267583.63342.0a

7. Slutsky JB, Barr JM, Femia AN, Marghoob AA. Large congenital melanocytic nevi: associated risks and management considerations. Semin Cutan Med Surg. 2010;29(2):79-84. doi:10.1016/j. sder.2010.04.007

8. Arad E, Zuker RM. The shifting paradigm in the management of giant congenital melanocytic nevi: review and clinical applications. Plast Reconstr Surg. 2014;133(2):367-376. doi:10.1097/01. prs.0000436852.32527.8a

9. Simons EA, Huang JT, Schmidt B. Congenital melanocytic nevi in young children: histopathologic features and clinical outcomes. $J \mathrm{Am}$ Acad Dermatol. 2017;76(5):941-947. doi:10.1016/j.jaad.2016.12.026

10. Barcot Z, Dakovic Bacalja I, Zupancic B, Bacalja V. Treating giant congenital nevus with integra dermal regeneration template in a 9-year-old girl. Int J Low Extrem Wounds. 2017;16(2):143-145. doi:10.1177/1534734617702259

11. Funayama E, Yamamoto Y, Oyama A, et al. Combination laser therapy as a non-surgical method for treating congenital melanocytic nevi from cosmetically sensitive locations on the body. Lasers Med Sci. 2019;34(9):1925-1928. doi:10.1007/s10103-019-02753-0
Clinical, Cosmetic and Investigational Dermatology

\section{Publish your work in this journal}

Clinical, Cosmetic and Investigational Dermatology is an international, peer-reviewed, open access, online journal that focuses on the latest clinical and experimental research in all aspects of skin disease and cosmetic interventions. This journal is indexed on CAS.
The manuscript management system is completely online and includes a very quick and fair peer-review system, which is all easy to use. Visit http://www.dovepress.com/testimonials.php to read real quotes from published authors. 